\title{
¡DE PRIMARIA A SECUNDARIA, HE AHÍ EL PROBLEMA!
}

\author{
M.Sc. Teresita Villalobos $H$.
}

Este artículo trata de la problemática que viven los estudiantes durante el proceso de transición de primaria a secundaria, aquí se presenta un análisis de una serie de reflexiones de estudiantes de tercer y cuarto ciclo de la educación costarricense acerca de la experiencia que viven y vivieron durante ese proceso y sus apreciaciones hacia los profesores.

También se plantea una forma de reducir el problema de adaptación de los estudiantes de sétimo año por medio de la articulación de los procesos de cambio a nivel social y didáctico que se dan en este nivel de enseñanza general básica.
This article deals with the problems students face in their transition from priman to secondary school. The paper analyses a series of comments made by $7-11$ grade students of the Costa Rican educational system in relation to the experiences they are having or had during the process and to their opinions about their teachers.

A proposal to diminish adaptation problems faced by 7 th grade students is also presented. What is suggested is that the social and teaching changes that occur at this level should be interconnected in order to deal with them.

* Máster en Educación con énfasis en la Enseñanza del Español como Segunda Lengua. Bachiller y licenciada en Sociología con énfasis en metodología.

Académica de la División de Educología del Centro de Investigación y Docencia en Educación (CIDE). Durante el año académico 2000 - 2001 laboró como profesora invitada en la Universidad Estatal de los Apalaches, en Carolina del Norte, Estados Unidos. 
"en diciembre apenas se gradúan de la primaria sintiéndose como niños y en febrero, a solo dos meses, ingresan a la secundaria como jóvenes adolescentes responsables, por lo que deben de cambiar rápidamente la condición de niños a adolescentes".

La investigación educativa ha sido un trabajo explorado en su mayoría por etnógrafos, antropólogos, sociólogos y otros profesionales; no obstante, poco a poco los maestros han incursionado en ella y les ha permitido transformar su práctica pedagógica, con su ayuda los docentes son capaces de romper con los paradigmas fundamentados en la simple instrucción, la investigación se convierte en una herramienta que le sirve para inno-

var, explicar, e interpretar los procesos educativos.

El propósito de este ensayo es dar a conocer las imágenes que tienen los estudiantes acerca de la experiencia que viven y vivieron durante el proceso de transición y adaptación de la primaria a la secundaria y sus apreciaciones hacia los profesores.

Está orientado a la reflexión y a la búsqueda de respuestas de sus propias vivencias, está basado en el análisis de entrevistas realizadas a estudiantes de tercer y cuarto ciclo de la educación costarricense, con este ensayo también se busca concientizar a los docentes y autoridades del Ministerio de Educación Pública, sobre cómo mejorar y satisfacer las expectativas de los estudiantes ante ese proceso de transición.

La información fue recolectada por estudiantes del curso de Investigación Educativa, de la Licenciatura en la Enseñanza de las Matemáticas del 2002, en diferentes colegios del país, tanto de áreas urbanas como rurales. Los colegios que estos estudiantes visitaron fueron los siguientes: Colegio Técnico Profesional de Puerto Viejo, Liceo de Santo Domingo de Heredia, Liceo Académico de Puriscal, Liceo Nuevo de Hatillo, Liceo Regional de Flores, Unidad Pedagógica José Rafael Araya Rojas de Tibás, Liceo de Belén, InstitutoBilingüe San Gerardo, Liceo Laboratorio Emma Gamboa de la Universidad de Costa Rica, Liceo Rodrigo Hernández de Barva, Colegio de Palmares, Liceo Ingeniero Manuel Benavides de Heredia y Liceo de San Isidro de Heredia.

Se trabajó con estudiantes de sétimo, octavo y noveno años con el fin de obtener una perspectiva más amplia acerca de lo que los estudiantes perciben sobre el proceso de transición tan significativo para los alumnos. Los datos obtenidos se recopilaron principalmente a través de la técnica de la entrevista cara a cara, pues es una técnica efectiva para recolectar la información necesaria 
y pertinente sobre la conducta, las prácticas y las acciones de las personas ante una situación especial. Además, la técnica es pertinente porque crea un ambiente de confianza, curiosidad y naturalidad entre el (a) entrevistador (a) y el (a) entrevistado (a).

Los estudiantes del curso "Investigación Educativa" fueron planteando varias preguntas para obtener los datos que les permitiría luego hacer las interpretaciones sobre las vivencias de los colegiales durante dicho proceso, para la interpretación de los datos se tomaron las siguientes preguntas:

1- ¿ Cómo has sentido el cambio de la escuela al colegio ?

2- ¿ Cuál dirías que fue tu primera sensación en el colegio ?

3- ¿Cómo te afectó el cambio de tener pocos maestros a tener muchos profesores?

4- ¿ Cómo fueron los primeros días en el colegio ?

5- ¿Qué opinas del colegio, de las normas, del uniforme? ¿Cómo te sientes con el uniforme?

6- ¿Cómo te tratan los profesores, cómo te trataban las maestras ?

7- ¿ Qué te da miedo del colegio ?

8- ¿ Si pudieras cambiar algo del colegio, qué cambiarías ?

9- ¿ Cuál ambiente te ha gustado más, el de la escuela o el del colegio?

$\mathrm{Al}$ analizar las respuestas de los estudiantes nos damos cuenta del significado que tiene para ellos esa transición de primaria a secundaria, para la interpretación de los datos no se hizo estrictamente pregunta por pregunta, sino que se hizo contemplado varias respuestas.

A la pregunta ¿cómo han sentido el cambio de la escuela al colegio? los estudiantes respondieron que les afecta mucho el hecho de que no están acostumbrados a recibir tantas materias y tener muchos profesores. Sufren un choque muy grande porque tampoco saben estudiar, debido a que tienen nuevas materias, y mucha más información en cada una de ellas; también experimentan un cambio de horarios al incrementar las horas de estudio y asistencia a clases, en algunos casos los estudiantes bajan las calificaciones y esto hace que muchos pierdan el año y dejen sus estudios.

Los estudiantes estaban acostumbrados a que sus padres les ayudaban a hacer tareas. En la secundaria es diferente, los muchachos vienen de una forma de enseñanza diferente con una sola maestra, y les es difícil adaptarse a una forma de enseñanza, donde cada uno de los profesores tiene un estilo propio. Es impactante también el hecho de que tienen que hacer muchos exámenes con abundante materia por aprenderse en tan solo una semana. 
Ante la pregunta: ¿cómo fueron los primeros días en el colegio? Muchos alumnos expresaron sentir deseos de regresar a la escuela durante los primeros días de clases en secundaria, debido al cambio tan drástico que vivieron "en diciembre apenas se gradúan de la primaria sintiéndose como niños y en febrero, a solo dos meses, ingresan a la secundaria como jóvenes adolescentes responsables, por lo que deben de cambiar rápidamente la condición de niños a adolescentes".

A la pregunta: ¿ cómo te tratan los profesores, cómo te tratan las maestras? Los jóvenes manifestaron que después de tener unas relaciones cálidas con sus maestras y compañeros pasan a tener unas relaciones frías con sus profesores y personal administrativo; y en algunos casos deben comenzar de cero a hacer amigos, situación que para unos es fácil, pero para otros es difícil.

Es muy interesante cuando los estudiantes responden sobre las normas y el uniforme, para ellos el reglamento de sus colegios son para respetarlos y los aceptan sin cuestionarles nada, pero si difieren en el control del uniforme, como es llevar las faldas por dentro, el largo de la enagua, uso de aretes, collares y maquillaje. Algunas muchachas expresan que no les gusta usar uniforme,porque no les gusta el color celeste y azul.

Cuando se les preguntó sobre cuál ambiente les ha gustado más, el de la escuela o del colegio, se interpretó que en cuanto al aspecto social y psicológico, los estudiantes también están viviendo un proceso de transición de niños a adolescentes que significa cambios en su persona. Llegan a la secundaria, a hacer amigos y vivir un proceso de socialización más amplio y algunos se sienten emocionalmente muy mal, y manifiestan mucho temor ante ese cambio. Cada etapa del ciclo vital plantea al ser humano problemas característicos y nuevas oportunidades de inserción en el mundo. La adolescencia constituye en nuestros tiempos un período de vida en el que se dan con mayor intensidad la interacción entre las tendencias del individuo y sus metas ( Krauskopf D. 1997 ).

Mientras que por otrolado, también, encontramos estudiantes que anhelaban ingresar a la secundaria para sentirse grandes y tener un poco más de libertad, ya que no les gusta que los traten como niños. Quieren estar más tiempo fuera de sus hogares, conocer gente, hacer nuevos amigos, ir a fiestas, bailes del colegio, tener novio o novia. Muchos prefieren asistir a la secundaria para superarse y no ir a hacer trabajos duros en el campo, como lo hacen sus padres, que es la experiencia que viven los muchachos de las zonas rurales.

Nuestro modelo educativo no toma en cuenta ningún período de transición entre preescolar, primaria, secundaria y universidad. No existe ninguna articulación entre ellos; por esta razón, para los profesores no resulta significativo ni digno de atención el reflexionar sobre ningún proceso de transición (Pérez. R. A. 1999). 


\section{Interpretaciones finales}

El proceso de transición y adaptación de los estudiantes de primaria a secundaria es un tema que nos llama a la reflexión, "la secundaria es uno de los elementos más importantes en el ambiente social de un joven, es un medio de avance económico y social que lleva a la vida adulta exitosa" (Papalia E. D. y Wendkos. S., 1999, pág. 582), pero también es motivo de fracaso escolar. de deserción, de discriminación, de baja autoestima, etc., ya que la adaptación de un ciclo lectivo a otro no existe en la práctica, aunque sí existe en la ley.

La Constitución Política de nuestro país en el artículo 77 (pág. 29) establece lo siguiente:

La educación pública será organizada como un proceso integral correlacionado en sus diversos ciclos, desde la preescolar hasta la universitaria.

En los problemas del proceso de adaptación y desarrollo intervienen aspectos como: un currículo divorciado de las necesidades educativas y culturales del estudiante, la conformación de las disciplinas o materias, el desarrollo de diversas nociones de mundo por parte de los docentes y alejadas de la realidad de los estudiantes y una falta de coordinación entre la primaria y la secundaria (Pérez R. 1999).

Los problemas se agravan con los estudiantes de sétimo y de décimo años. en estos niveles se están dando los peores resultados. Se supone que el tercer ciclo de la Educación General Básica debería estar estrechamente ligada con el segundo ciclo, cosa que no sucede en la práctica pedagógica.

Este proceso de transición que viven los estudiantes no ocurre solamente en Costa Rica, sino que también en diferentes países con modelos de un sistema educativo similar al nuestro, debido a la falta de articulación en los diferentes niveles. En lugar de tener un profesor y estar con los mismos niños durante toda la jornada, ahora se encuentra en un ambiente menos personal en donde profesores, aulas y compañeros cambian todo el día" (Papalia E. D. y Wendkos. S., 1999, pág. 582).

Con los siguientes datos vemos el grado de dificultad que se le presentan a los estudiantes de sétimo en ese proceso de adaptación de la escuela al colegio, con las cifras de 1998 que da el Departamento de Estadística del MEP. Solamente lograron aprobar el año lectivo el $44.4 \%$ y lo reprobaron el $21.1 \%$. En ese año la repitencia fue de el $17.1 \%$ y hubo una alarmante deserción del $19.8 \%$. Según estas cifras, para estos jóvenes que están viviendo una transformación en sus vidas y cuerpos, la superación de este otro problema conlleva el forjarse un futuro mejor por medio de la educación formal. 
La pedagogía del amor también juega un papel importante en este proceso. El maestro debe promover ese desarrollo socioafectivo para elevar la autoestima del joven con el fin de evitar la deserción y el fracaso escolar; existe una expulsión sutil (Pérez. R. A., 1999, pág. 23 ) con el discurso de la mala conducta, la indisciplina, las observaciones. "los agendazos". La incapacidad para aprender conduce a los alumnos hacia el abandono de la institución educativa.

Con el fin de evitar la deserción y el fracaso escolar, los docentes deben buscar estrategias metodológicas para que los estudiantes comprendan la materia, porque recordemos que en la escuela tienen una metodología diferente a la que usan en el colegio, pues solo se explica y el alumno tiene que tomar apuntes. Los nuevos estudiantes necesitan clases menos aburridas, más dinámicas, más creativas, con más participación del alumno, donde también pueda reflexionar, razonar, donde se promueva el pensamiento crítico. Es necesario que sean más sujetos que objetos en el salón de clase, para que ellos se sientan a gusto y quieran asistir a la secundaria. El alumno debe concientizarse de cuál es su papel en el proceso de enseñanza aprendizaje, ser actores y no espectadores. De esta manera, se estaría brindándole un sentido al estar en el aula aprendiendo y no memorizando contenidos para hacer un examen.

Una forma de reducir el problema de adaptación de los estudiantes de sétimio sería por supuesto articular la primaria y la secundaria, pero lo primero que se debe hacer es bajo un ambiente social, por ejemplo, que los niños de sexto realicen visitas al colegio y convivios con los estudiantes de sétimo para que entre estudiantes que se cuenten las experiencias que ellos vivieron y las posibles experiencias que los niños de sexto vivirán. Más que todo, debe haber actividades recreativas entre los sextos y los sétimos, que los maestros y profesores se involucren con charlas de orientación a los niños y que los profesores de todas las materias del colegio tengan una relación con los niños de sextò grado, donde se dé un acercamiento amigable entre ellos.

Los docentes que vayan a trabajar con sétimos deben tener conciencia de cuál es el proceso de desarrollo socioafectivo y de adaptación que los estudiantes están viviendo y contribuir a que ese proceso de transición no se vea como un problema, sino como eso, un proceso de adaptación a nuevas oportunidades de inserción en la sociedad. También, por los cambios físicos y emocionales que están viviendo los jóvenes, se constituya en un reto hacia el futuro y no en un obtáculo. 


\section{Referencias}

Rivera.G.S. 1999. Constitución Política de Costa Rica. San José. Editec. Editores S.A.

Departamento de Estadística. (1998). Indicadores educativos de 1998. San José. MEP.

Krauskopf D. 1995. La adolescencia y el ámbito escolar. Washington D.C. Publicación Cientifíca $N^{\bullet} 552$.

Papalia E. D. Y Wendkos.S. (1999). Psicología del desarrollo. Sétima edición. McGraw Hill. México.

Pérez, R.A. (1999). De la escuela al colegio. San José. Ministerio de Educación Pública.

Woods, P. (1986). La escuela por dentro. Barcelona. Editorial Paidós y Gérica S. A. 